\title{
HIF-1 $\alpha$ Activation Attenuates IL-6 and TNF- $\alpha$ Pathways in Hippocampus of Rats Following Transient Global Ischemia
}

\author{
Jihong Xing ${ }^{\mathrm{a}}$ Jian Lu \\ aDepartment of Emergency Medicine, The First Hospital of Jilin University, Changchun, bepartment of \\ Abdominal Surgery, Jilin Province Carcinoma Hospital, Changchun, China

\section{Key Words} \\ Cardiac arrest • Cardiopulmonary resuscitation • Hippocampus • Cytokines
}

\begin{abstract}
Background/Aims: This study was to examine the role played by hypoxia inducible factor-1 $(\mathrm{HIF}-1 \alpha)$ in regulating pro-inflammatory cytokines (PICs) pathway in the rat hippocampus after cardiac arrest (CA) induced-transient global ischemia followed by cardiopulmonary

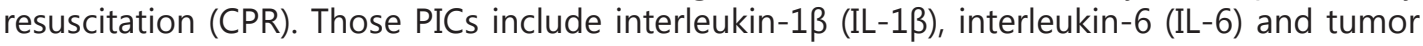
necrosis factor- $\alpha$ (TNF- $\alpha$ ). Methods: A rat model of CA induced by asphyxia was used in the current study. Following CPR, the hippocampus CA1 region was obtained for ELISA to determine the levels of HIF- $1 \alpha$ and PICs; and Western Blot analysis to determine the protein levels of PIC receptors. Results: Our data show that IL-1 $\beta$, IL- 6 and TNF- $\alpha$ were significant elevated in the hippocampus after CPR as compared with control group. This was companied with increasing of HIF- $1 \alpha$ and the time courses for HIF- $1 \alpha$ and PICs were similar. In addition, PIC receptors, namely IL-1R, IL-6R and TNFR1 were upregulated in CA rats. Also, stimulation of HIF-1 $\alpha$ by systemic administration of ML228, HIF-1 $\alpha$ activator, significantly attenuated the amplified IL-6/ IL-6R and TNF- $\alpha$ /TNFR1 pathway in the hippocampus of CA rats, but did not modify IL- $1 \beta$ and its receptor. Moreover, ML228 attenuated upregulated expression of Caspase- 3 indicating cell apoptosis evoked by CA. Conclusion: Transient global ischemia induced by CA increases the levels of IL-1 $\beta$, IL- 6 and TNF- $\alpha$ and thereby leads to enhancement in their respective receptor in the rat hippocampus. Stabilization of HIF-1 $\alpha$ plays a role in attenuating amplified expression IL-6R, TNFR1 and Caspase-3 in the processing of transient global ischemia. Results of our study suggest that PICs contribute to cerebral injuries evoked by transient global ischemia and in this pathophysiological process activation of HIF-1 $\alpha$ improves tissues against ischemic injuries. Our data revealed specific signaling pathways in alleviating CA-evoked global cerebral ischemia by elucidating that HIF- $1 \alpha$ plays an important role in regulating PIC signal pathways and Caspase-3. The subsequent induction of HIF-1 $\alpha$ and its target signals is likely a part of the intrinsic neuroprotective effects aimed at attenuating damage as a result of global cerebral ischemia. Thus, targeting one or more of these signaling molecules has clinical implications for treatment and improvement of CA-evoked global cerebral ischemia often observed in clinics.




\section{Cellular Physiology Cell Physiol Biochem 2016;39:511-520 \begin{tabular}{l|l} 
and Biochemistry Published online: July 07, 2016 & $\begin{array}{l}\text { (c) } 2016 \text { The Author(s). Published by S. Karger AG, Basel } \\
\text { www.karger.com/cpb }\end{array}$
\end{tabular} \\ Xing/Lu: Pro-Inflammatory Cytokines and Transient Global Ischemia}

\section{Introduction}

Pro-inflammatory cytokines (PICs) i.e., interleukins, lymphokines and cell signaling molecules are released by numerous cells including leukocytes, myocytes, microglia and astrocytes cells [1]. In particular, as mediators of immune and inflammatory reactions IL$1 \beta$, IL- 6 and TNF- $\alpha$ play an important role in responding to global ischemic stress $[2,3]$. These PICs modulate the responsiveness of many cell types in a number of diseases. During diseased states, PICs can recruit cells to inflammatory sites and modulate cell survival, division, proliferation and differentiation [4].

Hypoxia inducible factor-1 (HIF-1) as an important endogenous signaling protein contributes to pathophysiologic changes of homeostasis under conditions of oxygen deprivation [5-10]. Accumulated subunit HIF-1 $\alpha$ in the cellular nucleus and cytoplasm modulates the expression of several target genes that involve in neuroprotection, erythropoiesis, and apoptosis modulation $[11,12]$. Additionally, inadequate oxygen supply appears in the brain regions during global ischemia, which is associated with ischemiaevoked pathophysiologic changes $[13,14]$. Recent studies have demonstrated that HIF-1 $\alpha$ is expressed in the brain tissues including hippocampus, indicating that HIF- $1 \alpha$ is engaged in hippocampal apoptosis after induction of global ischemia [6,13-15]. Using a rat model of asphyxial cardiac arrest (CA), our recent study has further demonstrated that HIF-1 $\alpha$ is increased in the hippocampus of rats with CA [16]. Stabilization of HIF-1 $\alpha$ by systemic administration of ML228, an activator of HIF-1 $\alpha$ [17], enhances vascular endothelial growth factor (VEGF) thereby leading to upregulated protein expression of its receptor VEGFR-2 [16]. This is beneficial to brain ischemic injuries after CA followed by cardiopulmonary resuscitation (CPR).

In light of the precise mechanisms responsible for HIF- $1 \alpha$ in response to lacking of oxygen following CA, we examined the role played by HIF- $1 \alpha$ in regulating PIC pathways (namely, IL-1 $\beta$, IL-6 and TNF- $\alpha$; and their respective receptors IL-1R, IL-6R and TNFR1) in the rat hippocampus after CA induced- transient global ischemia followed CPR. We hypothesized that CA increases IL-1 $\beta$, IL- 6 and TNF- $\alpha$ and upregulates their receptors IL-1R, IL-6R and TNFR1, and that systemic administration of ML228 attenuates those exaggerated PIC pathways.

In addition, nucleus transcription factor such as Caspase- 3 is essential signaling pathways engaged in cell survival and hypoxia-induced apoptosis $[18,19]$. i.e., it has been reported that Caspase-3 expression was amplified in cortical neurons after brain ischemic injuries and inhibition of Caspase- 3 reduces the neuronal loss and brain edema [20,21]. Our recent study also demonstrated that Caspase- 3 is upregulated in in the rat hippocampus after CA [16]. Thus, we further hypothesized that ML228 lessens exaggerated expression of Caspase- 3 in the hippocampus of rats with CA by attenuating PIC signal pathways.

\section{Materials and Methods}

\section{Animal}

All the animal procedures were approved by the Institutional Animal Care \& Use Committee of Jilin University, which are in compliance with the Guideline for the Care and Use of laboratory Animals of the U.S. National Health Institute. Male Sprague-Dawley rats $(200-300 \mathrm{~g})$ were used in our experiments.

\section{Transient global ischemia}

The ischemia was produced by the CA model induced by asphyxia as described previously in our publication [16]. Rats were anesthetized with an isoflurane-oxygen mixture (2 - 5\% isoflurane in $100 \%$ oxygen). An endotracheal tube was first inserted and attached to a ventilator. The ventral tail artery was cannulated to monitor systemic arterial pressure. The right jugular vein was cannulated for a continuous infusion of saline (at a rate of $0.1 \mathrm{ml} /$ hour) to maintain baseline blood pressure and fluid balance. Body temperature was continuously monitored and maintained at $37^{\circ} \mathrm{C}$ with a heating pad and external heating lamps. Asphyxia was induced by stopping mechanical ventilation and clamping the tracheal tubes at the 


\section{Cellular Physiology Cell Physiol Biochem 2016;39:511-520 \begin{tabular}{c|c|c|} 
DOI: 10.1159/000445643 & $\begin{array}{l}\text { O 2016 The Author(s). Published by S. Karger AG, Basel } \\
\text { wwww.karger.com/cpb }\end{array}$
\end{tabular} \\ Xing/Lu: Pro-Inflammatory Cytokines and Transient Global Ischemia}

end of expiration. Resuscitation efforts began 6 min following CA was induced. For this purpose, rats were orotracheally intubated for mechanical ventilation accompanied by chest compression delivered by a mechanical compressor at a rate of $200 / \mathrm{min}$ for $5 \mathrm{~min}$. Once spontaneous heartbeat returned, epinephrine $(2 \mu \mathrm{g})$ was administered to achieve a mean arterial blood pressure of $>80 \mathrm{mmHg}$. Ventilation was adjusted for animals to regain spontaneous respiration and achieve normoxia. The animals that survived from this procedure were used for further interventions. For pain relief those rats received analgesic buprenorphine $(0.02 \mathrm{mg} / \mathrm{kg})$ subcutaneously immediately and every 6 hours for a 24-hour period after the asphyxial procedures. In the sham operated animals, the same surgical procedures were performed without cardiac arrest and resuscitation.

\section{Study interventions}

The first group of rats was used to examine the time courses of HIF-1 $\alpha$ and PICs responses to CA followed by CPR. The rats were sacrificed 0, 3, 6 and 24 hours after CPR, respectively ( $\mathrm{n}=8-15$ in each group). To examine the role of HIF- $1 \alpha$ the second group of rats was divided randomly ( $\mathrm{n}=10-15$ in each group) as follow. Sham-operated group: the same surgical procedures and endotracheal intubation were performed with no asphyxia and CPR. Saline control group: CA and CPR were performed and $1 \mathrm{ml}$ of saline (i.p., twice) was administered after CA. ML228 group: CA and CPR were carried out and $2 \mathrm{mg} / \mathrm{kg}$ of ML228 (i.p., twice) was injected after CA [16]. Note that the second injection was given 12 hours after CA in order to enhance the effects of this drug. At the end of each experiment, animals were sacrificed by overdose isoflurance followed by decapitation. Then, the brains were taken out to determine expression of HIF-1 $\alpha$, PICs and their receptors as well as Caspase- 3 in the hippocampus of rats. Note that the hippocampus CA1 region was used in this study.

In the third groups ( $\mathrm{n}=10-12$ in each group), following CA and CPR procedures rats were continued with an isoflurane-oxygen mixture and immobilized in a stereotaxic apparatus (David Kopf, USA). After making a midline incision, the skull was exposed and one burr hole was drilled. Following this, animals were cannulated with an L-shaped stainless steel cannula aimed at the lateral ventricle according to the coordinates: $3.7 \mathrm{~mm}$ posterior to the bregma, $4.1 \mathrm{~mm}$ lateral to the midline, and $3.5 \mathrm{~mm}$ under the dura. The guide cannula was fixed to the skull using dental zinc cement and jewelers' screw. Then, the cannula was connected to an osmotic minipump (Alzet pump brain infusion kit, DURECT Inc., Cupertino, CA) with polycarbonate tubing. The pumps were placed subcutaneously between the scapulae, and loaded with vehicle (aCSF) as control or 10 $\mu$ g of SC144 (gp130 inhibitor used to attenuate IL-6R activation) and $10 \mu \mathrm{M}$ of etanercept [22] (ETAN, TNF- $\alpha$ receptor antagonist, Tocris Co.), respectively. SC144 and ETAN were delivered at $0.25 \mu \mathrm{l}$ per hour. This intervention allowed animals to receive continuous intracerebroventricular (ICV) infusion via the osmotic minipumps before brain tissues were removed.

\section{ELISA measurements}

All the tissues from individual rats were sampled for the analysis. In brief, the hippocampus of the rats was removed. Total protein was then extracted by homogenizing hippocampus sample in ice-cold radioimmunoprecipitation assay buffer with protease inhibitor cocktail kit. The lysates were centrifuged and the supernatants were collected for measurements of protein concentrations using a bicinchoninic acid assay reagent kit.

The levels of HIF- $1 \alpha$ were determined using an ELISA assay kit (Abcam Co.) according to the provided description and modification. Briefly, polystyrene 96-well microtitel immunoplates were coated with affinity-purified polyclonal rabbit anti-HIF-1 $\alpha$ antibody. Parallel wells were coated with purified rabbit IgG for evaluation of nonspecific signal. After overnight incubation, plates were washed. Then, the diluted samples and the HIF-1 $\alpha$ standard solutions were distributed in each plate. The plates were washed and incubated with anti-HIF-1 $\alpha$ galactosidase. Then, the plates were washed and incubated with substrate solution. After incubation, the optical density was measured using an ELISA reader. This method was also employed to examine the levels of IL-1 $\beta$, IL- 6 and TNF- $\alpha$ according to the provided description and modification (Promega Corp. Madison, WI).

\section{Western blot analysis}

After being denatured by heating at $95^{\circ} \mathrm{C}$ in an SDS sample buffer, the supernatant samples was loaded onto 4-20\% Mini-Protean TGX Precast gels and then electrically transferred to a polyvinylidene fluoride 


\section{Cellular Physiology Cell Physiol Biochem 2016;39:511-520 \begin{tabular}{c|c|c|} 
DOI: 10.1159/000445643 & $\begin{array}{l}\text { O 2016 The Author(s). Published by S. Karger AG, Basel } \\
\text { wwww.karger.com/cpb }\end{array}$
\end{tabular} \\ Xing/Lu: Pro-Inflammatory Cytokines and Transient Global Ischemia}

membrane. The membrane was then incubated overnight with primary antibodies: rabbit anti-IL-1R, antiIL-6R, anti-TNFR1 and anti-Caspase-3/anti-cleaved Caspase-3 (Abcam Co., diluted 1:200 - 1:500). After being fully washed, the membrane was incubated with horseradish peroxidase-linked anti-rabbit secondary antibody and visualized for immunoreactivity. The membrane was stripped and incubated with mouse anti$\beta$-actin to show equal loading of the protein. The bands recognized by the primary antibody were visualized by exposure of the membrane onto an X-ray film. Then, the film was scanned and the optical densities of IL-1R, IL-6R, TNFR1, Caspase-3, cleaved Caspase- 3 and $\beta$-actin bands were determined using the NIH Scion Image Software. Then, values for densities of immunoreactive bands/ $\beta$-actin band from the same lane were determined. Each of the values was then normalized to a control sample.

\section{Histochemistry}

After brains were removed, the hippocampus was postfixed in 4\% paraformaldehyde for 2 days at room temperature. Coronal sections ( $5-\mu \mathrm{m}$ thick) were cut from each block. In order to localize Caspase-3 and cleaved Caspase- 3 , the sections were washed in $0.5 \%$ hydrogen peroxide and placed in PBS containing $1 \%$ normal goat serum and $0.1 \%$ Triton X-100 (PNT). They were then incubated in a primary rabbit antiCaspase-3 (diluted 1:1000) and anti- cleaved Caspase-3 (diluted 1:500) antibodies. After sections were rinsed in PBS and in PNT, they were incubated in biotinylated goat anti-rabbit immunoglobulin G (diluted 1:200), washed in PBS, and incubated with avidin-biotinylated horseradish peroxidase complex solution. After a serial rinse in PBS and Tris (hydroxymethyl) aminomethane buffer, immunostaining was made visible by incubating sections with hydrogen peroxide and 3,3'-diaminobenzidine.

\section{Data statistical analysis}

Experimental data were analyzed using one-way repeated measures analysis of variance (ANOVA). As appropriate, Tukey's post hoc tests were used. All values were presented as mean \pm SEM. For all analyses, differences were considered significant at $P<0.05$. All statistical analyses were performed using SPSS for Windows version 20.0.

\section{Results}

\section{Animal survival rate}

The survival rate of 24 hours was 71\% (32/45rats) in CA; 76.4\% (42/55) in CA + ML228 group; and $77.4 \%$ (24/31) in CA + SC144 and ETAN. Data obtained from those survival rats were included for the analysis in this report.

Time courses of expression of HIF-1 $\alpha$ and PICs

Figure 1 shows that HIF- $1 \alpha$, IL- $1 \beta$, IL- 6 and TNF- $\alpha$ were significantly increased in the hippocampus 3, 6 and 24 hours after CA $(P<0.05 v s$. control, $\mathrm{n}=8-12$ in each group). There were no significant differences observed in HIF-1 $\alpha$ and those PICs between 3 and 6 hours following CA. As compared with 3 and 6 hours, the levels of HIF- $1 \alpha$ were less 24 hours after induction of CA. Nonetheless, administration of ML228 significantly restored the declined HIF-1 $\alpha(P<0.05 v s$. no treatment, $\mathrm{n}=8$-15 in each group). In addition, ML228 significantly attenuated the amplified levels of IL- 6 and TNF- $\alpha(P<0.05$ vs. no treatment, $n=8-15$ in each group), but not IL-1 $\beta$ in the in the hippocampus 24 hours after CA.

\section{Expression of PIC receptors}

Figure 2 illustrates that induction of CA significantly increased the protein expression of IL-1R, IL-6R and TNFR1 in the hippocampus $(P<0.05$, control rats vs. CA rats; $\mathrm{n}=10-12$ in each group). When ML228 was injected to stabilize HIF-1 $\alpha$, enhancement in expression of IL-6R and TNFR1 was significantly attenuated in the hippocampus of CA rats. Nonetheless, amplified expression of IL-1R evoked by CA tended to be attenuated by ML228, but was not significantly altered ( $P>0.05$ vs. rats without treatment, $\mathrm{n}=10-15$ in each group). 
Fig. 1. Induction of CA amplified the levels of HIF- $1 \alpha$ and PICs in the hippocampus. Systemic administration of ML228 enhanced HIF-1 $\alpha$ and attenuated increased PICs in rats 24 hours after $\mathrm{CA} .{ }^{*} \mathrm{P}<0.05$ vs. control rats and 0 hour of $\mathrm{CA}$ rats. $\dagger \mathrm{P}<0.05$ vs. 24 hours of CA rats without treatment. The number of rats $=8-15$ in each group.
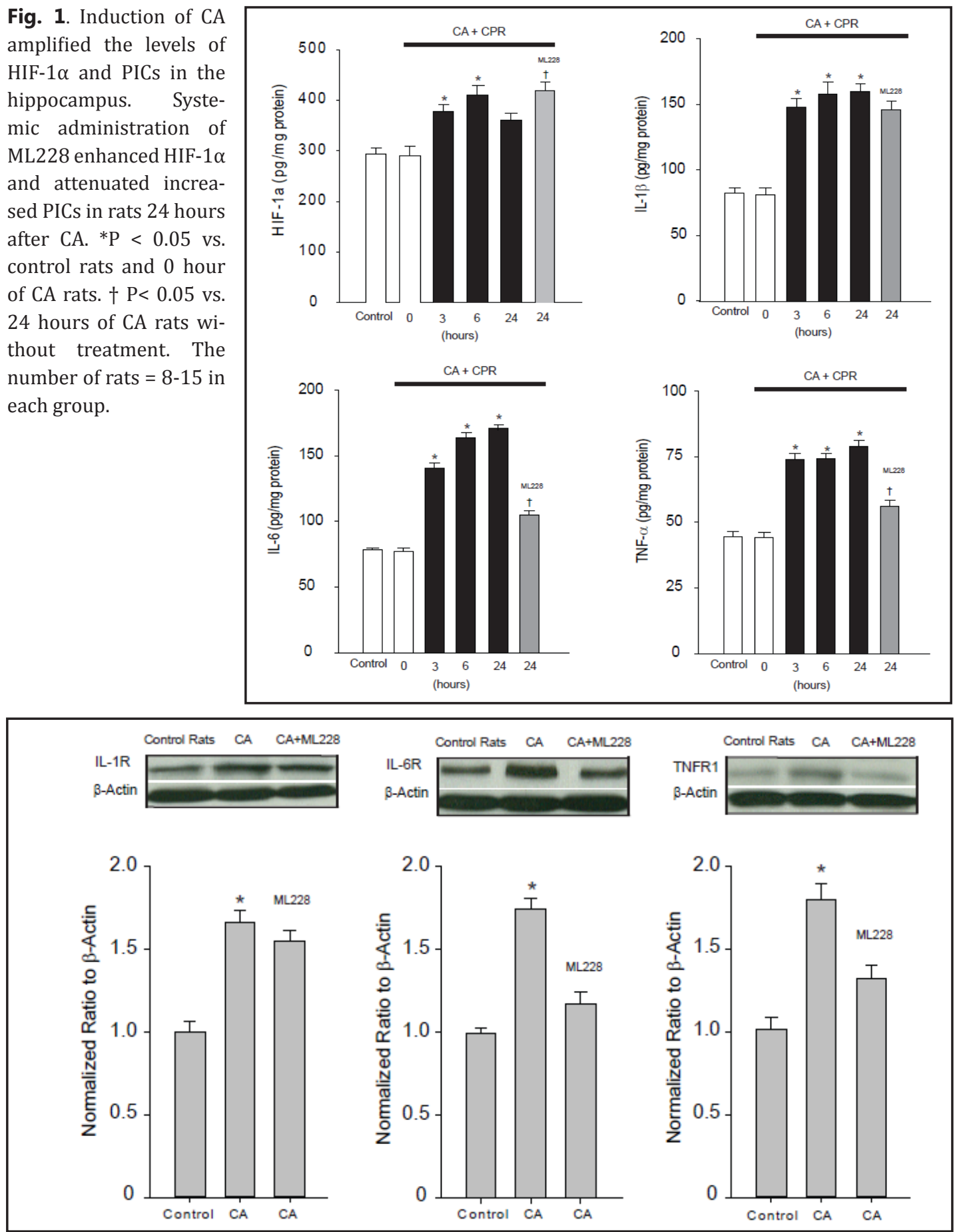

Fig. 2. The protein expression of IL-1R, IL-6R and TNFR1 in the hippocampus tissues was increased in rats 24 hours after CA. ML228 blunted IL-6R and TNFR1, but had no significant effects on IL-1R. Top panels indicate representative bands and bottom panels indicate averaged data. ${ }^{*} \mathrm{P}<0.05$, indicated CA rats with no treatment vs. control rats for IL-1R group; ${ }^{*} \mathrm{P}<0.05$, indicated CA rats with no treatment vs. control rats and CA rats with ML228. The number of rats $=10-15$ in each group.

\section{Expression of Caspase-3}

Figure $3 \mathrm{~A}$ illustrates that induction of CA significantly increased the protein expression of Caspase- 3 and cleaved Caspase- 3 in the hippocampus $(P<0.05$, control rats vs. CA rats;

\section{KARGER}


Fig. 3. The protein expression of Caspase-3 and cleaved Caspase- 3 in the hippocampus tissues was significantly increased in rats 24 hours after CA followed by CPR. Injection of ML228 attenuated Caspase-3 and cleaved Caspase-3 expression. (A) Top panels indicate representative bands and bottom panels indicate averaged data. ${ }^{*} \mathrm{P}<0.05$, indicated CA rats with no treatment vs. control rats and CA rats with ML228. The number of rats $=10-12$ in each group. (B\&C) Representative images showing Caspase-3 and cleaved Caspase- 3 staining in the hippocampus (control rat, CA rat and CA rat with injection of ML228) under a light microscopy.

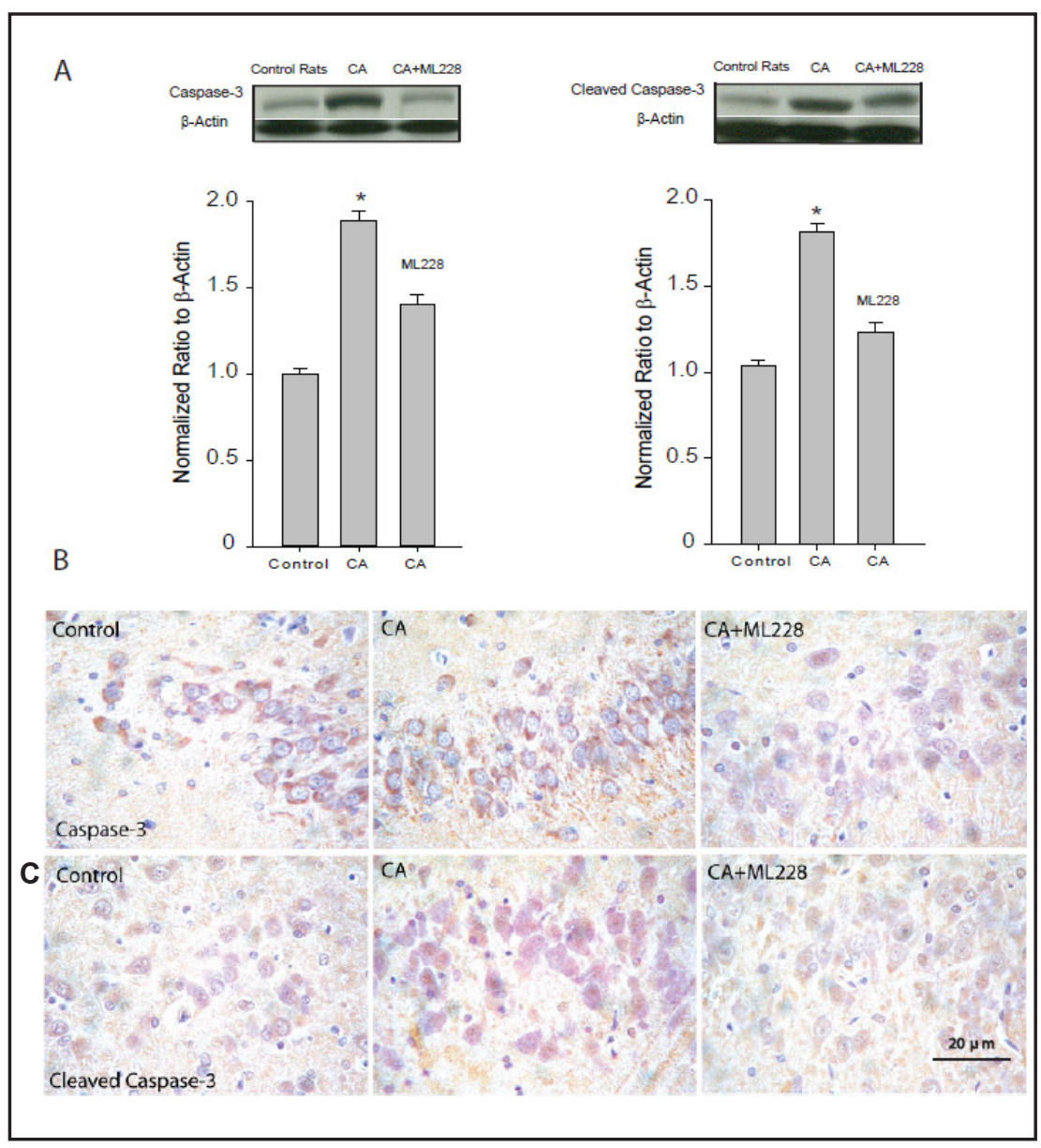

Fig. 4. Caspase-3 and cleaved Caspase-3 were significantly increased in rats 24 hours after CA as compared with control animals. Blocking activities of IL-6R and TNFR1 by lateral ventricular infusion of respective SC144 and ETAN decreased the effects of CA-enhanced Caspase-3. Top panels show typical bands that are representative of expression of Caspase-3 and cleaved Caspase-3 in the hippocampus of three groups of rats. Bottom panels are averaged data. ${ }^{*} \mathrm{P}<0.05$ vs. control rats and CA rats with the prior SC144 and ETAN. The number of rats $=10-12$ in each group.
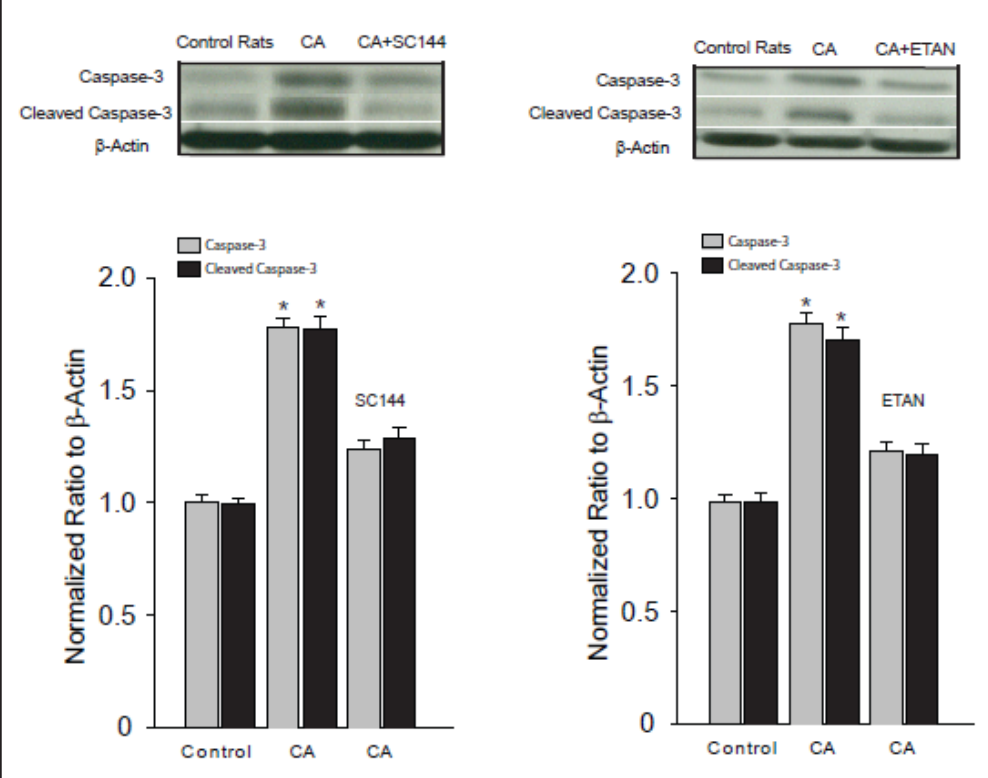

$\mathrm{n}=10-12$ in each group). As ML228 was injected, expression of both Caspase- 3 and cleaved Caspase- 3 was significantly decreased. Note that there were no significant differences in the levels of Caspase- 3 and cleaved Caspase- 3 in control rats and rats that received ML228. 


\section{Cellular Physiology Cell Physiol Biochem 2016;39:511-520 \\ \begin{tabular}{l|l} 
and Biochemistry Published online: July 07, 2016 & $\begin{array}{l}\text { D } 2016 \text { The Author(s). Published by S. Karger AG, Basel } \\
\text { www.karger.com/cpb }\end{array}$
\end{tabular} \\ Xing/Lu: Pro-Inflammatory Cytokines and Transient Global Ischemia}

Furthermore, Fig. 3B\&C show that we localized immunostaining of Caspase-3 and cleaved Caspase- 3 in the hippocampus of control rats and CA rats without and with ML228 treatment. This result further shows the inhibitory effects of ML228 on Caspase-3.

In order to elucidate the effects of IL- 6 and TNF- $\alpha$ pathway on Caspase- 3 in the process of transient global ischemia, SC144 and ETAN were infused into the brain via ICV. Figure 4 illustrates that SC144 ( $\mathrm{n}=12)$ and ETAN $(\mathrm{n}=12)$ significantly attenuated the amplified protein expression of Caspase- 3 and cleaved Caspase- 3 in the hippocampus of CA rats $(P<$ 0.05 vs. control animals; $n=10$ ). Insignificant differences were observed in Caspase- 3 and cleaved Caspase- 3 expression between control animals and animals infused with respective SC144 and ETAN.

\section{Discussion}

Using a rat model we showed that CA increased HIF- $1 \alpha$ and PICs including IL-1 $\beta$, IL-6 and TNF- $\alpha$ in the hippocampus CA1 region. CA also augmented a representative nucleus transcription factor indicating cell apoptosis, namely Caspase- 3 as well as a cleaved form of Caspase-3. Notably, systemic administration of ML228 attenuated enhancement of PIC receptors, IL-6R and TNFR1, and Caspase- 3 evoked by CA. Blocking individual IL-6R and TNFR1 activities also attenuated Caspase-3 expression in the hippocampus of CA rats. Overall, we suggest that activated HIF- $1 \alpha$ is likely to play a beneficial role in improving neuronal cell injuries induced by CA via engagement of PICs and Caspase-3 mechanisms.

Apoptosis represents a prominent form of cell death and is generally observed in the brain tissues after transient global ischemia [14]. Caspases, a family of thiol proteases, play an important role in regulating the apoptotic cascade [23], and brain ischemic stress activates neuronal caspases. The processing of pro-caspase- 3 to its active form is considered a key processing in the death-signaling cascade [24]. Caspase-3 is a predominant target involved in the reactive oxygen species-mediated ischemia induced apoptosis in neuronal cells, and neuronal apoptosis results in blood brain barrier dysfunction, inflammation and oxidative cascades and thereby leading to brain damage $[25,26]$. It has been reported that Caspase- 3 expression was exaggerated in cortical neurons after brain ischemic injuries and inhibition of Caspase- 3 reduces the neuronal loss and brain edema [20, 26]. In addition, a greater number of neurons that are stained with terminal deoxynucleotidyl transferase dUTP Nick End Labeling (TUNEL) are found in hippocampus as apoptosis is engaged in the pathological process of global ischemia-induced neuronal loss due to CA [14]. Thus, Caspase-3 expression is considered as an indicator of neuronal apoptosis with respect to global ischemia.

During CA occurs, blood flow and oxygen delivery are abruptly halted, which leads to systemic ischemic injury in various organs including brain [27]. Although CPR is applied inadequate blood flow and tissue oxygen delivery still persist due to myocardial dysfunction, hemodynamic instability and microvascular dysfunction. In response to hypoxic stress, HIF-1 $\alpha$ was synthesized and the expression of its downstream product such as VEGF is upregulated and remains elevated $[15,28]$. This contributes to neuroprotection against brain ischemic conditions by improving the permeability of blood brain barrier, reducing brain edema formation and promoting the recovery of brain injuries [29]. Our recent study showed that stabilizing HIF-1 $\alpha$ significantly attenuated increases of cleaved Caspase- 3 and TUNEL evoked by induction of CA as ML228 was given [16]. As a result, this process improved neurological deficits and neuronal edema observed in rats after CA.

PICs, IL-1 $\beta$, IL-6 and TNF- $\alpha$ are responsive to global ischemic stress [3], which is likely to modulate the responsiveness of many cell types in a number of diseases. For instance, during diseased states, PICs can recruit cells to inflammatory sites and modulate cell survival, division, proliferation and differentiation [4]. In the current study, we examined the role played by HIF- $1 \alpha$ in regulating pathophysiological process via PIC signal pathways. The data of our current study demonstrated IL-1 $\beta$, IL- 6 and TNF- $\alpha$ are elevated in the hippocampus of animals 3-24 hours after CA followed by CPR. The time courses for increases of HIF-1 $\alpha$ and 


\section{Cellular Physiology Cell Physiol Biochem 2016;39:511-520 \begin{tabular}{l|l} 
DOI: 10.1159/000445643 & $\begin{array}{l}\text { O 2016 The Author(s). Published by S. Karger AG, Basel } \\
\text { www.karger.com/cpb }\end{array}$
\end{tabular} \\ Xing/Lu: Pro-Inflammatory Cytokines and Transient Global Ischemia}

PICs were similar. Interestingly, stabilization of HIF- $1 \alpha$ by ML228 attenuated IL- 6 and TNF- $\alpha$ and their receptor expression as well as Caspase-3. Our prior study suggests that attenuation of the hippocampal Caspase-3 improves impaired neurological functions and neuronal edema caused by CA [16]. While HIF-1 $\alpha$ is synthesized during hypoxic stress, it is degraded [30]. Thus, maintaining HIF-1 $\alpha$ in hypoxic and ischemic tissues has a potential significance to improve tissues injuries due to low oxygen supplies likely by attenuating upregulated PIC pathways. Data of our current study further provide evidence suggesting that stabilization of HIF-1 $\alpha$ and its target signal pathways is likely involved in neuroprotective effects and attenuating damages evoked by global cerebral ischemia.

IL-6 complexes with membrane-bound or soluble IL-6R to activate cells expressing the signal transducer glycoprotein (gp130) [31, 32]. Most cells are devoid of membrane-bound IL-6R and are thus unresponsive to IL-6; however, they can still react to IL-6 complexed with a soluble form of the IL-6R (sIL-6R) to activate gp130, a pathway called "trans-signaling" [31]. Thus, in the current study we used SC144, a gp130 inhibitor, to block IL-6-mediated signal transduction in order to examine engagement of the IL-6R in Caspase-3 expression in the hippocampus of CA rats.

TNF- $\alpha$ produces its effects via activation of two TNF- $\alpha$ receptor subtypes, TNFR1 and TNFR2 [33]. TNFR1 is expressed exclusively on neuronal cells and plays a functional role, whereas TNFR2 is located predominantly on macrophages and/or monocytes in response to inflammation. Thus, in our current study application of ETAN attenuates Caspase-3 induced by CA, it is likely via TNFR1. In addition, we observed distinct expression of TNFR1 receptors in the hippocampus of rats after CA. Nonetheless, we have observed that blocking IL-6R or TNFR1 pathways lessened amplified Caspase-3 expression in the hippocampus evoked by CA as ML228 did.

\section{Conclusion}

Transient global ischemia induced by CA significantly increases the levels of HIF-1 $\alpha$, PICs and their receptors, and Caspase- 3 in the hippocampus. HIF- $1 \alpha$ appears to be greater at least 3 hours after CA and persists. Stabilization of HIF- $1 \alpha$ can attenuate the protein expression of PIC receptors, IL-6R and TNFR1, and Caspase-3 in the hippocampus of rats 24 hours following CA. Blocking IL-6R and TNFR1 also attenuates Caspase-3 expression in the hippocampus of CA animals. Our data suggest that HIF- $1 \alpha$ play an important role in alleviating cerebral ischemia reperfusion injury by attenuating neuronal apoptosis likely via PIC pathways. Our data further indicate that stimulation of HIF-1 $\alpha$ is likely a part of the intrinsic neuroprotective effects aimed at attenuating damages evoked by global cerebral ischemia. Accordingly, targeting one or more of these signaling molecules has clinical significance for treatment and management of CA-evoked global cerebral ischemia often observed in clinics.

\section{Disclosure Statement}

None.

\section{References}

1 Wang CX, Shuaib A: Involvement of inflammatory cytokines in central nervous system injury. Prog Neurobiol 2002;67:161-172.

2 Fu CY, He XY, Li XF, Zhang X, Huang ZW, Li J, Chen M, Duan CZ: Nefiracetam Attenuates Pro-Inflammatory Cytokines and GABA Transporter in Specific Brain Regions of Rats with Post-Ischemic Seizures. Cell Physiol Biochem 2015;37:2023-2031. 


\section{Cellular Physiology Cell Physiol Biochem 2016;39:511-520 \begin{tabular}{l|l} 
DOI: 10.1159/000445643 & $\begin{array}{l}\text { O 2016 The Author(s). Published by S. Karger AG, Basel } \\
\text { www.karger.com/cpb }\end{array}$
\end{tabular} \\ Xing/Lu: Pro-Inflammatory Cytokines and Transient Global Ischemia}

3 Saito K, Suyama K, Nishida K, Sei Y, Basile AS: Early increases in TNF-alpha, IL-6 and IL-1 beta levels following transient cerebral ischemia in gerbil brain. Neurosci Lett 1996;206:149-152.

4 Oppenheim JJ: Cytokines: past, present, and future. Int J Hematol 2001;74:3-8.

5 Ceradini DJ, Kulkarni AR, Callaghan MJ, Tepper OM, Bastidas N, Kleinman ME, Capla JM, Galiano RD, Levine JP, Gurtner GC: Progenitor cell trafficking is regulated by hypoxic gradients through HIF-1 induction of SDF1. Nat Med 2004;10:858-864.

6 Li X, Huo X, Zhang C, Ma X, Han F, Wang G: Role of continuous high thoracic epidural anesthesia in hippocampal apoptosis after global cerebral ischemia in rats. Cell Physiol Biochem 2014;34:1227-1240.

7 Manalo DJ, Rowan A, Lavoie T, Natarajan L, Kelly BD, Ye SQ, Garcia JG, Semenza GL: Transcriptional regulation of vascular endothelial cell responses to hypoxia by HIF-1. Blood 2005;105:659-669.

8 Yan J, Huang Y, Lu Y, Chen J, Jiang H: Repeated administration of ketamine can induce hippocampal neurodegeneration and long-term cognitive impairment via the ROS/HIF-1alpha pathway in developing rats. Cell Physiol Biochem 2014;33:1715-1732.

9 Zhang W, Qian C, Li SQ: Protective effect of SGK1 in rat hippocampal neurons subjected to ischemia reperfusion. Cell Physiol Biochem 2014;34:299-312.

10 Zhou X, Gu J, Gu Y, He M, Bi Y, Chen J, Li T: Human Umbilical Cord-Derived Mesenchymal Stem Cells Improve Learning and Memory Function in Hypoxic-Ischemic Brain-Damaged Rats via an IL-8-Mediated Secretion Mechanism Rather than Differentiation Pattern Induction. Cell Physiol Biochem 2015;35:2383-2401.

11 Hota KB, Hota SK, Srivastava RB, Singh SB: Neuroglobin regulates hypoxic response of neuronal cells through Hif-1[alpha]- and Nrf2-mediated mechanism. J Cereb Blood Flow Metab 2012;32:1046-1060.

12 Northington FJ, Chavez-Valdez R, Martin LJ: Neuronal cell death in neonatal hypoxia-ischemia. Ann Neurol 2011;69:743-758.

13 Ding XD, Zheng NN, Cao YY, Zhao GY, Zhao P: Dexmedetomidine preconditioning attenuates global cerebral ischemic injury following asphyxial cardiac arrest. Int J Neurosci 2016;126:249-256.

14 Gao CJ, Niu L, Ren PC, Wang W, Zhu C, Li YQ, Chai W, Sun XD: Hypoxic preconditioning attenuates global cerebral ischemic injury following asphyxial cardiac arrest through regulation of delta opioid receptor system. Neuroscience 2012;202:352-362.

15 Chavez JC, LaManna JC: Activation of hypoxia-inducible factor-1 in the rat cerebral cortex after transient global ischemia: potential role of insulin-like growth factor-1. J Neurosci 2002;22:8922-8931.

16 Liu X, Lu J, Xing J: Stabilization of HIF-1 $\alpha$ Modulates VEGF and Caspase-3 in Hippocampus of Rats Following Transient Global Ischemia Induced by Asphyxial Cardiac Arrest. Life Sci 2016;151:243-249.

17 Theriault JR, Felts AS, Bates BS, Perez JR, Palmer M, Gilbert SR, Dawson ES, Engers JL, Lindsley CW, Emmitte KA: Discovery of a new molecular probe ML228: an activator of the hypoxia inducible factor (HIF) pathway. Bioorg Med Chem Lett 2012;22:76-81.

18 Aggarwal BB: Nuclear factor-kappaB: the enemy within. Cancer Cell 2004;6:203-208.

19 Baldwin AS: Control of oncogenesis and cancer therapy resistance by the transcription factor NF-kappaB. J Clin Invest 2001;107:241-246.

20 Dong YS, Wang JL, Feng DY, Qin HZ, Wen H, Yin ZM, Gao GD, Li C: Protective effect of quercetin against oxidative stress and brain edema in an experimental rat model of subarachnoid hemorrhage. Int J Med Sci 2014;11:282-290.

21 Simard MJ, Geng Z, Kyoon Woo S, Ivanova S, Tosun C, Melnichenko L, Gerzanich V: Glibenclamide reduces inflammation, vasogenic edema, and caspase-3 activation after subarachnoid hemorrhage. J Cereb Blood Flow Metab 2008;29:317-330.

22 Yang X, Hei C, Liu P, Song Y, Thomas T, Tshimanga S, Wang F, Niu J, Sun T, Li PA: Inhibition of mTOR Pathway by Rapamycin Reduces Brain Damage in Rats Subjected to Transient Forebrain Ischemia. Int J Biol Sci 2015;11:1424-1435.

23 Salvesen GS: Caspases: opening the boxes and interpreting the arrows. Cell Death Differ 2002;9:3-5.

24 Ghavami S, Hashemi M, Ande SR, Yeganeh B, Xiao W, Eshraghi M, Bus CJ, Kadkhoda K, Wiechec E, Halayko AJ, Los M: Apoptosis and cancer: mutations within caspase genes. J Med Genet 2009;46:497-510.

25 Bosoi CR, Yang X, Huynh J, Parent-Robitaille C, Jiang W, Tremblay M, Rose CF: Systemic oxidative stress is implicated in the pathogenesis of brain edema in rats with chronic liver failure. Free Radic Biol Med 2012;52:1228-1235. 


\section{Cellular Physiology Cell Physiol Biochem 2016;39:511-520 \begin{tabular}{l|l} 
DOI: 10.1159/000445643 & $\begin{array}{l}\text { O 2016 The Author(s). Published by S. Karger AG, Basel } \\
\text { www.karger.com/cpb }\end{array}$
\end{tabular} \\ Xing/Lu: Pro-Inflammatory Cytokines and Transient Global Ischemia}

26 Marc Simard J, Geng Z, Kyoon Woo S, Ivanova S, Tosun C, Melnichenko L, Gerzanich V: Glibenclamide reduces inflammation, vasogenic edema, and caspase-3 activation after subarachnoid hemorrhage. J Cereb Blood Flow Metab 2008;29:317-330.

27 Nolan JP, Neumar RW, Adrie C, Aibiki M, Berg RA, Böttiger BW, Callaway C, Clark RSB, Geocadin RG, Jauch EC, Kern KB, Laurent I, Longstreth WT, Merchant RM, Morley P, Morrison LJ, Nadkarni V, Peberdy MA, Rivers EP, Rodriguez-Nunez A, Sellke FW, Spaulding C, Sunde K, Hoek TV: Post-cardiac arrest syndrome: Epidemiology, pathophysiology, treatment, and prognostication. Resuscitation 2008;79:350-379.

28 Pichiule P, Agani F, Chavez JC, Xu K, LaManna JC: HIF-1 alpha and VEGF expression after transient global cerebral ischemia. Adv Exp Med Biol 2003;530:611-617.

29 Peng Z-R, Yang AL, Yang Q-D: The effect of hyperbaric oxygen on intracephalic angiogenesis in rats with intracerebral hemorrhage. J Neurol Sci 2014;342:114-123.

30 Jaakkola P, Mole DR, Tian YM, Wilson MI, Gielbert J, Gaskell SJ, Kriegsheim A, Hebestreit HF, Mukherji M, Schofield CJ, Maxwell PH, Pugh CW, Ratcliffe PJ: Targeting of HIF-alpha to the von Hippel-Lindau ubiquitylation complex by 02-regulated prolyl hydroxylation. Science 2001;292:468-472.

31 Rose-John S, Heinrich PC: Soluble receptors for cytokines and growth factors: generation and biological function. Biochem J 1994;300:281-290.

32 Taga T, Hibi M, Hirata Y, Yamasaki K, Yasukawa K, Matsuda T, Hirano T, Kishimoto T: Interleukin-6 triggers the association of its receptor with a possible signal transducer, gp130. Cell 1989;58:573-581.

33 MacEwan DJ: TNF receptor subtype signalling: differences and cellular consequences. Cell Signal 2002;14:477-492. 